\section{Making Class and Place in Contemporary China}

\section{Roberta Zavoretti}

Rural-to-urban migrants in China are often depicted as being poor, uncivilised, and having a lower level of 'human quality' than those with urban household registration. Policy-makers carefully strategise in order to produce ruralto-urban migrants as a homogeneous category. However, the use of this term obscures more than it illuminates, as it homogenises complex social realities.
In the People's Republic of China the media, official state policies, and propaganda, as well as the policies of market organisations, define rural-to-urban migrants (nongmingong) as essentially lacking 'human quality' (suzhi). They are depicted as being poor, uncivilised, backwards, and hopelessly bound to their rural roots. In China, the nongmingong paradigm also evokes the spectre of Maoist egalitarianism. This implicitly reminds Chinese people that post-Mao inequality should be recognised as the motor of 'development', and that it has allowed people to get rich or, to paraphrase Deng Xiaoping, it has allowed some to 'get rich first'. Western media and academia have largely drawn on the paradigm of the rustic, plain, and hopelessly marginalised nongmingong, identifying them with a specifically Chinese 'underclass'. As Michael Stewart has observed in his study of the plight of Romany people of Eastern Europe, the use of this term, however, may obscure more than it illuminates in terms of social exclusion, as it homogenises complex social realities.

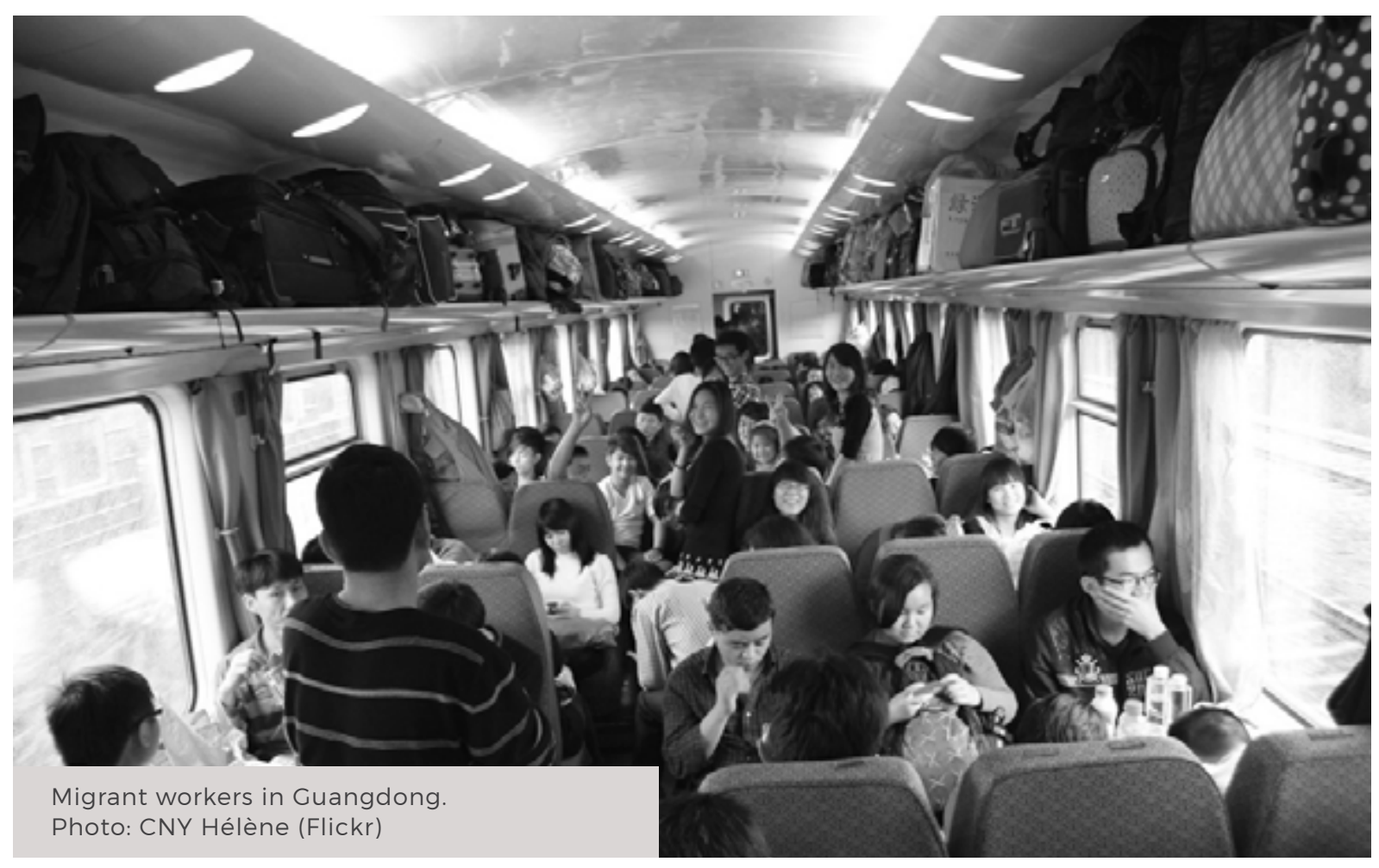




\section{Displacements of Class Meanings}

Since the 1990s, ethnographers have devoted much attention to the predicament of migrant factory workers in South China. Pun Ngai, for example, argues that this group constitutes a new working class whose subordinate position is determined by the interplay of ethnicity, gender, and residence status. These sensitive and influential ethnographies, however, portray the specific experiences of life and labour in Guangdongbased factories, rather than providing a general picture of migrant labour in China. General depictions of China's nongmingong as a socially homogeneous group are constantly confronted with the ever-growing heterogeneity and presence of migrants in the labour force. The phenomenon of labour migration in China involves people who differ by local origin, employment sector, income, educational level, gender, and age, to mention just a few factors.

In present-day China, the state-sponsored discursive production of migrant labourers as a 'real' and homogeneous social group sustains the promotion of the hegemonic social model of an ideally emerging 'middle class'. This trope implies high disposable income and home ownership, as well as publicly recognised professional status, top-level education and the highly valued quality of taste. In other words, it embodies the ability to compete and to choose as a high-quality consumer. Yet the discursive opposition between the nongmingong paradigm and the trope of middle classness must be produced without mentioning 'class' (jieji), a term that China-based policy, media, and academic production routinely avoid, and replace with the less conflictive term 'social stratum' (jieceng). To quote Sherry Ortner, the use of the policy category of nongmingong contributes to the continuous 'displacement of class meanings' into other discursive fields, such as gender, geographical background, ethnicity, and sexuality, in order to produce a class-based order without mentioning class.

\section{Household Registration Today}

The household registration (hukou) system has long allowed administrative institutions to identify rural-born city dwellers as a group. However, following the social and economic changes of the last forty years, as well as the various reforms of hukou at the local level, a debate has emerged about the link between residence status and the reproduction of social inequality. Following the radical Reformled changes in urban-based employment and social security provision, the hukou system is no longer used to stop rural residents from moving into the cities. Urban residence status is increasingly being commoditised through policies linked to the opening up of the housing and employment markets. Four decades of market-oriented policies have brought about a profound redefinition of social relations and a rapid process of social segmentation in the countryside as well as in the city.

Some scholars have associated urban hukou status with the idea of 'citizenship', thus echoing a larger debate on migration, citizenship, and globalisation. This debate illuminates the dynamics of state-market relations at a global level, while being relevant to China as well. Saskia Sassen's analysis of migrant service sector workers in 'global cities' distinguishes between a top end of high-flying 'global managers' and a bottom end of low-status service workers whose existence is the bedrock of the current global economic system. This latter group is denied full citizen rights and is therefore, by definition, vulnerable to exploitation and to specific forms of state policing. Notably, the state's policing role survived the rolling back of nation-states prescribed by the current 


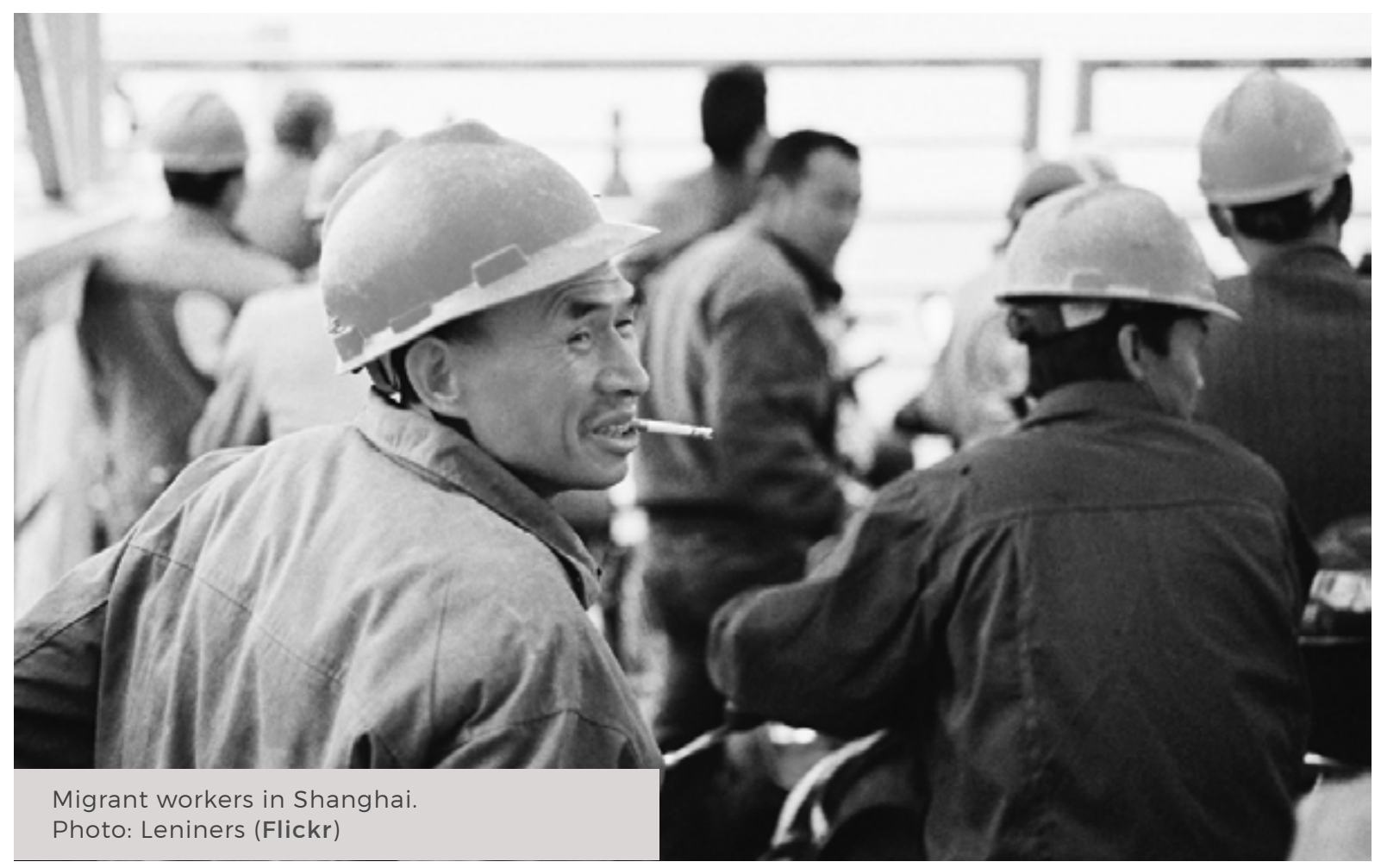

neoliberal policy trend. The neoliberal state is thus not antagonistic to, but rather complicit with global market forces and transnational institutions. This synergy between state and market in neoliberal times implies an altered idea of the citizen as a self-regulating, selfpromoting competitor and consumer, and thereby a noticeable redefinition of the value of citizenship. In this view, Sassen ultimately suggest that citizenship may gradually lose importance in the lives of migrants due to the neoliberal restructuring of state-market relations.

\section{Governing Inequalities}

In post-Mao China the restructuring of state-market relations-and accordingly of the relationships of both state and market with citizens-brought about a specific form of governance that reconciles the state's promotion of neoliberal subjectivities with the perpetuation of socialist discursive practices and political structures. The persistence of the household registration system allows state policy to cast hukou status-rather than class, for example-as a proxy for social positionality. While residence status still plays an important role in the definition of social positionality, however, urban residence is gradually ceasing to represent a guarantee of economic and social rights, as Solinger anticipated in her study of the work unit in the early 1990s.

Following the gradual dismantlement of the work unit, the state has increasingly made access to resources and services not a matter of residence, but of individual responsibility towards the family. According to this model of governance, each individual should compete to secure jobs and invest sensibly in his/ her family's long-term security, and also by participating in market-mediated insurance schemes. In this context, identifying 'urban residence status' with citizenship-based full civil, social and economic rights obscures the role that equally important variables play in the formation of social inequality, such as class, connections, gender, education, etc. 
These assets may be far better guarantees in terms of securing social and economic rights, including the right to be recognised as an 'urban citizen'.

\section{Nongmingong as a Strategic Discourse}

The development of China's state-led capitalism and the dramatic increase of inequality witnessed in Chinese society has led to the emergence of unprecedented forms of social exclusion-even among the once protected urban residents. During the Maoist era, urban residence status guaranteed the provision of a large array of services, including employment and housing. The main channel for rural to urban mobility was supposed to be higher education. Rural youngsters, however, faced enormous challenges to get a formal education in their villages, and only few determined and lucky ones were able to access universities. Four decades of economic reforms fundamentally changed the nature of social inequality and the role that residence status plays in it. During the pre-reform era, holding urban residence enabled citizens to claim housing (although often of poor quality) from the state; nowadays it is the ability to purchase property on the housing market that allows many, if not all, to access urban residence. Purchasing housing is also a strategy to situate oneself in a highly unequal and segmented society.

Local authorities throughout the country have been gradually reforming hukourelated provisions, leading to a de facto commoditisation of residence. However, the nongmingong remain a central category in state policy and media discourse. Local policy-makers carefully strategise in order to produce and maintain the social order. Policies that produce rural-to-urban migrants as a homogeneous category remind urban residents that these 'outsiders' may constitute a social problem; they also prompt both rural and urban residents to see each other as competitors rather than as possible allies on the basis of overlapping socioeconomic positions. In addition, grouping citizens according to the rural/urban binary allows the state to deflect attention from the increasing complexity and deepening of inequality in the city as in the village.

\section{Roberta Zavoretti}

Roberta Zavoretti is the author of Rural Origins, City Lives. Class and Place in Contemporary China (University of Washington Press, 2016). Her present research deals with the entanglements of gender and class formation in contemporary urban China. 